\title{
Pre-Surgical Sensorimotor Training for Patients Undergoing Total Hip Replacement: A Randomised Controlled Trial
}

Citation for published version (APA):

Bitterli, R., Sieben, J. M., Hartmann, M., \& Bruin, E. D. (2011). Pre-Surgical Sensorimotor Training for Patients Undergoing Total Hip Replacement: A Randomised Controlled Trial. International Journal of Sports Medicine, 32(9), 725-732. https://doi.org/10.1055/s-0031-1271696

Document status and date:

Published: 01/09/2011

DOI:

10.1055/s-0031-1271696

Document Version:

Publisher's PDF, also known as Version of record

\section{Document license:}

Taverne

Please check the document version of this publication:

- A submitted manuscript is the version of the article upon submission and before peer-review. There can be important differences between the submitted version and the official published version of record.

People interested in the research are advised to contact the author for the final version of the publication, or visit the DOI to the publisher's website.

- The final author version and the galley proof are versions of the publication after peer review.

- The final published version features the final layout of the paper including the volume, issue and page numbers.

Link to publication

\footnotetext{
General rights rights.

- You may freely distribute the URL identifying the publication in the public portal. please follow below link for the End User Agreement:

www.umlib.nl/taverne-license

Take down policy

If you believe that this document breaches copyright please contact us at:

repository@maastrichtuniversity.nl

providing details and we will investigate your claim.
}

Copyright and moral rights for the publications made accessible in the public portal are retained by the authors and/or other copyright owners and it is a condition of accessing publications that users recognise and abide by the legal requirements associated with these

- Users may download and print one copy of any publication from the public portal for the purpose of private study or research.

- You may not further distribute the material or use it for any profit-making activity or commercial gain

If the publication is distributed under the terms of Article 25fa of the Dutch Copyright Act, indicated by the "Taverne" license above, 


\section{Pre-Surgical Sensorimotor Training for Patients Undergoing Total Hip Replacement: A Randomised Controlled Trial}

Authors

Affiliations

\author{
R. Bitterli ${ }^{1}$, J. M. Sieben ${ }^{2}$, M. Hartmann ${ }^{1}$, E. D. de Bruin ${ }^{3}$
}

${ }^{1}$ Kantonsspital Liestal, Switzerland

${ }^{2}$ Department of Anatomy \& Embryology, Maastricht University, Maastricht, The Netherlands

${ }^{3}$ Institute of Human Movement Sciences and Sport, ETH Zurich, Switzerland
Key words

total hip endoprosthesis

- osteoarthritis

physical therapy

orthopaedics

- rehabilitation accepted after revision

January 13, 2011

\section{Bibliography}

DOI http://dx.doi.org/

10.1055/s-0031-1271696

Published online:

May 31, 2011

Int J Sports Med 2011; 32:

725-732 @ Georg Thieme

Verlag KG Stuttgart · New York

ISSN 0172-4622

\section{Correspondence}

\section{Dr. Judith M. Sieben, PhD}

Department of Anatomy \& Embryology

Maastricht University

P.O. Box 616

6200 MD Maastricht

The Netherlands

Tel.: + 31/433/88 1056

Fax: + 31/433/88 4134

j.sieben@maastrichtuniversity.nl

\section{Abstract}

$\nabla$

The aim of this study was to investigate whether pre-operative, sensorimotor training results in improved physical function, quality of life, sensorimotor function and reduced disability in total hip replacement patients. 80 subjects awaiting total hip replacement at a Swiss hospital were recruited for this randomised controlled trial. The intervention group participated in a pre-operative home exercise sensorimotor training programme; the control group received no therapy. Primary outcome measure was physical function, secondary outcome measures were quality of life, disability and sensorimotor function. Outcomes were measured using generic and disease-specific questionnaires as well as

\section{Introduction}

$\nabla$

The success of modern hip replacement is based on 40 years of orthopaedic experience. Progress in both surgical techniques and the materials used has gradually increased the lifespan of the prostheses and made this procedure one of the most cost-effective surgical treatments in modern health care [37]. In Switzerland alone, more than 15000 total hip endoprostheses (THEP) are fitted annually [1].

There is a marked lack of knowledge about the effect of physiotherapy applied before the procedure $[2,11]$. In addition, little is known about how hip replacement affects patients' quality of life. Gocen et al. [18] found that an 8-week presurgical strength and mobility training programme enabled patients post-surgically to perform transfer activities one day earlier and to climb stairs one day earlier than controls. Two studies $[17,40]$ involving 8 -week pre-surgical strength and endurance training programmes resulted in increased flexibility, ability to walk and WOMAC (Western Ontario McMaster Osteo- objectively assessed balance ability. Measurements were taken one day before surgery and 10 days, 4 and 12 months after surgery. The intervention showed improved quality of life and sensorimotor function before surgery. These effects were lost following surgery. The intervention group experienced more disability at 4 months than the control group. At one year follow-up group-membership influenced quality of life scores depending on the measurement-timepoint. It can be concluded that no useful effect was identified for a pre-operative sensory-motor training-programme. The psychological aspects following total hip replacement need to be considered in order to facilitate coping-strategies, reduce unrealistic expectations and increase satisfaction. arthritis Index) scores pre-surgically and 3 weeks post-surgically.

The effectiveness of a sensorimotor pre-surgical training programme on THEP rehabilitation has not been evaluated yet. The sensorimotor system includes "sensory, motor and central integration and processing components involved in maintaining joint homeostasis during functional activity" [24]; in sensorimotor training all these components are stimulated. A sensorimotor training programme has been shown to have a positive influence on strength, and improves the ability to perform activities of daily living and balance in the elderly [19]. Fitting a THEP impairs sensorimotor abilities, though it does not affect proprioception $[23,31,42]$. This makes it reasonable to ask whether hip replacement patients would benefit from a pre-surgical sensorimotor exercise programme.

Our study aims to show whether pre-surgical sensorimotor experience has positive post-surgical effects on physical activities, physical complaints (disability), quality of life and sensorimotor function. We assume as our first 
hypothesis that trained individuals will have improved self-evaluated physical, social and mental function up to 4 months after surgery due to their pre-surgical sensorimotor experience. The training will give the training group pre-surgical improved postural stability which will be retained up to 4 months after surgery determined by measurement of objective balance skills. Our second hypothesis, based on clinical observations, is that the benefits derived from the comprehensive post-surgical rehabilitation programme along with the gradual resumption of dayto-day and work activities will surpass the limited effects of the pre-surgical general (not individualised) sensorimotor programme, so that the values for the 2 groups will converge by a year after surgery.

\section{Material and Methods \\ $\nabla$}

\section{Study design and sampling}

Eighty men and women took part in this randomised controlled trial, all of whom were fitted with a THEP between June 2004 and March 2007 at the Cantonal Hospital in Liestal, Switzerland (see $\bullet$ Fig. 1). Inclusion criteria were unilateral arthrosis or femoral head necrosis, first and unilateral THEP. Patients who had had previous surgery on the affected joint, who had been fitted with hip, knee or ankle joint prostheses, for whom a double-sided THEP had been planned, who were due to undergo the procedure in fewer than 3 weeks, who would only be able to follow the training programme for fewer than 15 days or who were suffering from neurological complaints were excluded from the study. Potential participants were informed about the purpose of the study verbally and in writing by the instructors. They confirmed in written consent that they would participate in the study on a voluntary basis and without receiving compensation.

\section{Intervention and control conditions}

The training group (TR) followed a pre-surgical sensorimotor training programme at home, while the control group ( $\mathrm{CO}$ ) received no therapy. On the day before the surgery (the day of admission to hospital), both groups, in accordance with standard clinical procedure, were given brief verbal information by the instructors about the course of events after surgery and the risk of luxation, and were instructed about standing up from a supine position and about walking with forearm crutches. After surgery, both groups received the standard follow-up treatment from the physiotherapy team, which involved full loading for both cemented and uncemented prostheses following the standard therapy protocol used in this hospital. After discharge from hospital, the participants could choose whether to attend an outpatient rehabilitation programme or a rehabilitation clinic. Post-discharge care was not protocolised but consisted of usual care therapeutic modalities.

\section{Pre-surgical training programme}

The training programme was a so-called minimal intervention strategy, demanding minimal training effort over a period varying from 2 to 6 weeks with daily exercises at home after 2 verbal and written instruction sessions. The standard (not individual-

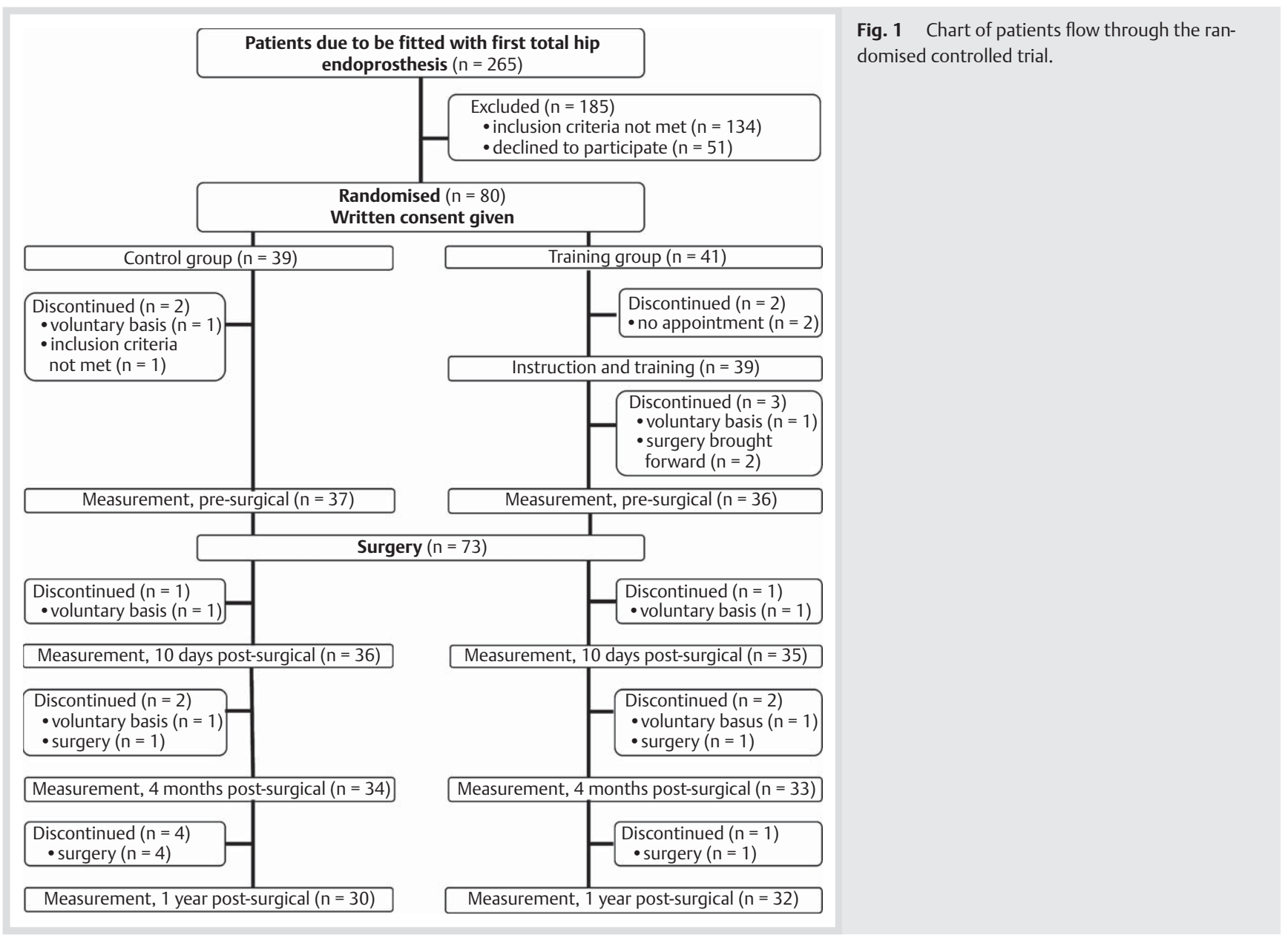


ised) programme contained 6 exercises developed for this study (see $\odot$ Fig. 2), which did not require the use of any training aids. The purpose of the exercises was to promote awareness of the position and movement of the hip joint and of its musculature. Each exercise should be performed twice daily with 10 repetitions or until pain sets in [39], without any progression. The extent of training and any problems encountered were recorded by each participant in a training logbook [29].

\section{Outcome measures}

\section{Questionnaires}

The participants in the study reported on their subjective state of health with the aid of the Medical Outcomes Study 36-Item Short-Form Health Survey (SF-36) and the Western Ontario McMaster Osteoarthritis Index (WOMAC) questionnaire. These 2 questionnaires are both well suited for use in hip replacement patients $[6,11,12,32]$. The generic SF-36 gives more extensive information for follow-up studies lasting longer than 6 months after the THEP than the disease-specific WOMAC $[5,6]$. Both instruments are reliable, valid and responsive and available in German translation [5, 7, 11,12,32,38]. The SF-36 gives information on 8 domains of health and well-being, the WOMAC on 3 domains. The sign of the WOMAC global index was reversed, so that high values correspond to good health in both questionnaires.

\section{Balance test device}

Sensorimotor skills contribute to the ability to balance when standing. The Biodex Balance System (BBS; produced by Biodex Medical Systems, New York) quantifies the ability to maintain
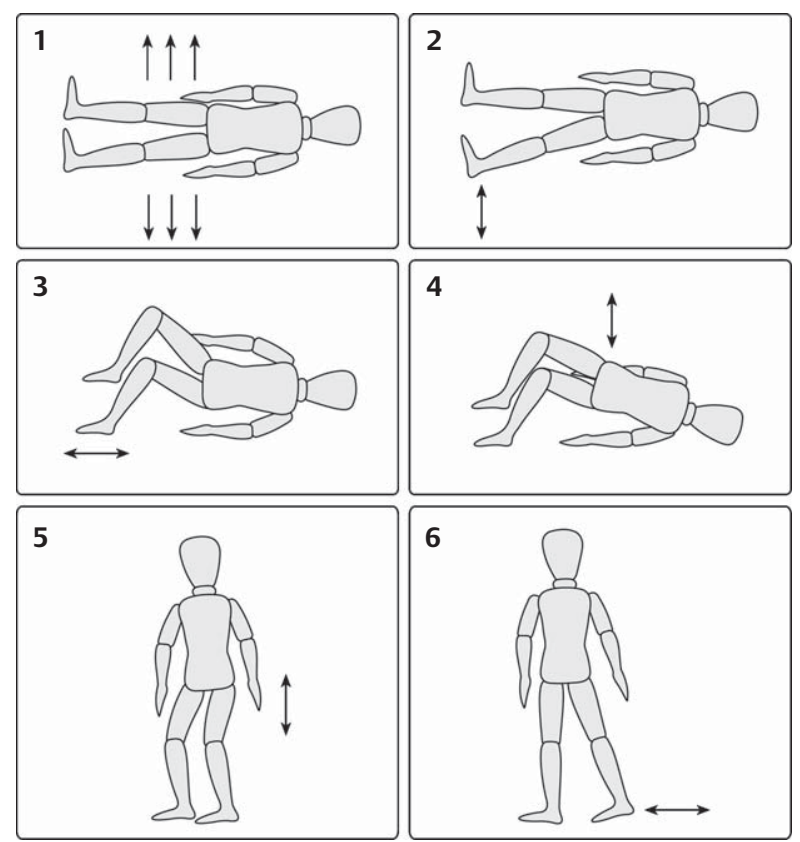

Fig. 2 Training programme.

Legend: Performed in supine position: 1 = Tense muscles of legs and buttocks; 2 = Move affected leg out to side and back on supporting surface; 3 = Raise knees, move foot backwards and forwards on supporting surface; 4 = Make a "bridge" (raise buttocks from supporting surface). Performed while standing: 5 = Stand upright with legs slightly apart, bend hips and knees and then straighten up again; 6 =Stand on unaffected leg and move other leg out to the side and back. one's balance on an unstable surface. In the static mode the BBS measures the angular displacement of the centre of gravity. From the degrees of tilt about the anterior-posterior and mediallateral axes, the anterior-posterior stability index (APSI), the medial-lateral stability index (MLSI) and the overall stability index (OSI) is calculated [4]. The participants received support from visual feedback displayed on a screen. Each test lasted $20 \mathrm{~s}$. The participants completed 3 trial repetitions prior to the actual test, to rule out short-term learning effects [33]. The test was performed standing barefoot in the most comfortable position. This device is regarded as a reliable, valid measurement tool $[13,21,35]$.

\section{Follow-up}

Measurements were scheduled at the same time as the usual medical checks on the day before surgery (day of admission) as well as at 8-10 days (before discharge) and 4 and 12 months after surgery. Two physiotherapists (one of whom was the author $\mathrm{RB})$ gave the participants the necessary instructions and performed the follow-up measurements according to the study protocol. The questionnaires were sent to the participants a few days before each appointment.

\section{Primary outcome}

Physical functioning

In the present hip replacement study, the main parameter evaluated will be the physical functioning domain of the SF-36, which includes 10 items.

\section{Secondary outcome Quality of life}

The remaining 7 domains of the SF-36 questionnaire were used as secondary outcome measures, expressing general quality of life. We used a modified acute version of the SF-36, with only 3 items relating to physical functioning and one item for pain, for the measurements made 10 days after surgery.

\section{Physical disability}

Functional problems were assessed by means of the global WOMAC index. For the measurements made 10 days after surgery, a modified version of the WOMAC index, with only 10 items relating to physical functioning, was used; items relating to activities that are not applicable to a hospital setting (for example "shopping") were removed.

\section{Sensorimotor function}

Balance skills measured with the aid of the Biodex Balance System were used to provide an objective check on the intervention. Using the most stable setting (level 8), the variables "overall stability index" (OSI) and "medial-lateral stability index" (MLSI) were evaluated for the purposes of this study.

\section{Randomisation, blinding and ethical approval}

The patients involved in the study were assigned to either one of the 2 groups with the aid of a randomisation table [14]. A person blinded for group allocation anonymised the data. None of the hospital staff was aware of the status (TR or CO) of the participants. The participants were requested not to reveal their allocation to any of the staff members.

The study meets ethical standards as stated by Harris and Atkinson [20]. The Cantonal Ethics Commission in Basel, Switzerland approved the study protocol. 


\begin{tabular}{|llll|}
\hline Characteristics & Training group & Control group & Total \\
\hline number of participants & 41 & 39 & 80 \\
\hline age in years, $\mathrm{M} \pm \mathrm{SD}($ range) & $65.37 \pm 10.77(37-85)$ & $68.42 \pm 9.74(40-86)$ & $66.8 \pm 10.3$ \\
\hline body mass index, $\mathrm{kg} / \mathrm{m}^{2} \pm \mathrm{SD}$ (range) & $27.63 \pm 3.60(20-40)$ & $27.07 \pm 3.56(18-36)$ & $27.4 \pm 3.6$ \\
\hline number of women & 19 & 12 & 31 \\
\hline number of men & 22 & 27 & 49 \\
\hline number of cemented prosthesis shafts & 31 & 24 & 55 \\
\hline number of non-cemented prosthesis shafts & 10 & 15 & 25 \\
\hline number of non-cemented prosthetic cups & 41 & 39 & 80 \\
\hline length of stay in hospital in days, $\mathrm{M} \pm \mathrm{SD}$ (range) & $14.6 \pm 2.5(11-23)$ & $14.6 \pm 2.6(8-22)$ & $14.7 \pm 2.5$ \\
\hline
\end{tabular}

Table 1 Characteristics of participants in both groups.

Legend: $\mathrm{M}=$ mean, $\mathrm{SD}=$ standard deviation

\section{Statistical methods}

Based on power estimation calculations, the number of participants was set to be 32 per group (difference 10 points, power $=0.75$, effect size $r=0.3$, alpha $=0.05$; [3]). To anticipate any possible loss to follow-up 40 patients per group were included. The 2 variables of the balance test and the 9 variables of the questionnaires were subjected to parametric analysis. The first hypothesis was tested using an independent t-test to test for differences between groups before surgery and single-factor repeated-measures analysis of variance for the second and third follow-up. The second hypothesis was tested using analysis of variance for the 3 post-surgical checks. Analyses of covariance were carried out using the control variables age and gender to take the slight differences in age and gender between the groups into account. Corrected analyses were performed only in case of significant influence of covariables. The group effect (betweensubjects effect) as well as the interaction effect between group and measurement time point (within-subjects effect) were considered. Effect sizes were determined by means of Cohen's $d$ and Pearson's $r[9,28]$, where $r=0.1$ or $d=0.2$ corresponds to a small effect, $\mathrm{r}=0.3$ or $\mathrm{d}=0.5$ to a medium effect and $\mathrm{r}=0.5$ or $\mathrm{d}=0.8$ to a large effect $[9,30]$. Correlations between selected parameters were tested. An intention-to-treat analytical approach was persued, and calculations were performed using the Statistical Package for Social Sciences for Windows software (SPSS, version 15.0 ), using an alpha of 0.05 (2-sided).

\section{Results \\ $\nabla$}

\section{Subject descriptives}

The randomisation yielded 2 groups that were similar in terms of size, personal characteristics and clinical characteristics (see $\odot$ Table 1). Sixty-two of the 80 participants (77.5\%) could be followed up to one year after surgery (see $\odot$ Fig. 1). Reasons for dropout in CO were polyneurpathy $(n=1)$, surgery $(n=1)$, free will $(n=3)$, contralateral total hip or knee replacement $(n=4)$, and in the TR group training time $(n=4)$, free will $(n=3)$ and contralateral hip replacement $(\mathrm{n}=2)$.

In all cases a lateral transgluteal surgical approach was used. Three patients in TR suffered complications (post-surgical haematoma; pain and ossification around the prosthetic joint; venous thrombosis in the lower leg), but completed the study.

\section{Duration of training and compliance}

Participants in the TR had an average of 33.5 days $(\mathrm{SD}=21.0$, range $=15-146$, median $=29$ ) at their disposition for the exercises. If the single outlier of 146 days was excluded from the analysis, the mean value changed to 30.3 days $(S D=8.5$, range $=15-57$, median=29). According to the information recorded in the training logbooks, the TR performed the prescribed exercises once or twice a day for 1100 of the total of 1206 days available, without outlier on 963 of 1060 days (corresponding to 91 or $90.9 \%$ respectively of the maximum possible). Three participants showed a strikingly low training frequency ( 6 out of 27 possible days, 18 out of 35 and 13 out of 30 ), due to lack of time. One person trained for 137 out of the 146 days available (due to the fact that surgery had been postponed). Ten participants ( $25.7 \%$ ) failed to perform their exercises on 1 or 2 days, while 9 participants (23.0\%) showed gaps ranging from 3 to 21 days in their training schedules. Six participants reported pain in certain exercises on 1-2 days and reduced the number of repetitions for these exercises accordingly.

\section{Outcome measures}

In the next paragraphs corrected analyses taking age and sex into account as covariates are only presented if appropriate (covariate p-value $<0.05$ ), otherwise the uncorrected results are reported.

\section{Primary outcome}

Physical functioning (SF-36)

As shown in $\odot$ Fig. 3, TR showed a better mean physical functioning before surgery $(M=43.3, S D=18.3)$ than $C O(M=40.0$, $\mathrm{SD}=20.6)$. This difference was not significant $(\mathrm{t}(69)=-0.74$, $\mathrm{p}=0.47, \mathrm{r}=0.08, \mathrm{~d}=0.16)$. Until 4 months after surgery $\mathrm{CO}$ showed a positive trend $(\mathrm{F}(1,61)=3.61, \mathrm{p}=0.06, \mathrm{r}=0.24, \mathrm{~d}=0.49)$. The training effect reduced further up to one year after surgery $(F(1,55)=2.14, p=0.15, r=0.19, d=0.39)$.

\section{Secondary outcome}

Quality of life (SF-36)

TR suffered significantly less pain on average before surgery $(\mathrm{M}=44.1, \mathrm{SD}=12.0)$ than $\mathrm{CO}(\mathrm{M}=36.8, \mathrm{SD}=12.7), \mathrm{t}(69)=-2.50$, $p<0.05, r=0.28, d=0.59$. The scores for the other domains were throughout lower for TR, indicating a poorer self-reported condition. However, these differences were not significant.

By 4 months after surgery, the pain level diminished for both groups, and the difference between the 2 was no longer significant. TR reported a lower level of mental health $(F(1,64)=4.46$, $\mathrm{p}<0.05, \mathrm{r}=0.26, \mathrm{~d}=0.54)$. Furthermore, mental health scores showed, after correction for age and $\operatorname{sex}(\mathrm{p}<0.05)$, an interaction effect between group membership and follow-up time point $(F(1,62)=4.38, p<0.05, r=0.26, d=0.54)$. It can be explained by the markedly worse self-estimation of TR 10 days after surgery, while both groups improved by 4 months after surgery and reported practically equally good levels. Vitality data showed a 


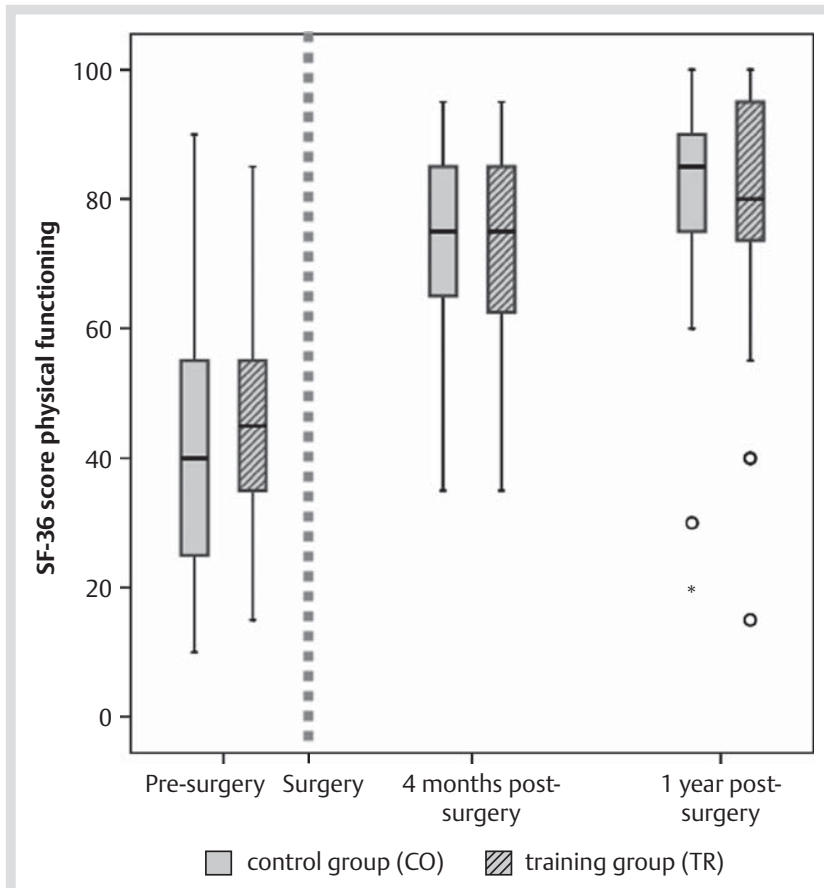

Fig. 3 Boxplot of physical functioning for the training (TR) and control (CO) group, 1 day pre-surgical, 4 months and 1 year post-surgical. Legend: Boxplots: horizontal lines mark medians, boxes display 25-75 percentile (= interquartile range IQR), whiskers mark lowest/highest value within 1.5 IQR from box, rounds mark outliers (1.5-3.0 IQR), asterisks mark extremes (>3.0 IQR). High values correspond to good physical functioning. Note that $x$-axis intervals are not to scale.

similar course, but without a significant difference between groups and without interaction effect.

One year post-surgery, there was a significant interaction effect between group and follow-up time point regarding vitality $(\mathrm{F}(1$, $58)=6.18, \mathrm{p}<0.05, \mathrm{r}=0.31, \mathrm{~d}=0.65)$ and mental health $(\mathrm{F}(1$, $56)=7.91, p<0.05, r=0.35, d=0.75)$, the latter after correction for age and sex $(p<0.05)$. This reflects the fact that the values of both variables for TR were lower than for CO 10 days post-surgery, equal to $\mathrm{CO}$ at 4 months, and higher than $\mathrm{CO}$ one year postsurgery. For all other SF-36 domains, both groups converged further during the follow-up period.

\section{Disability (WOMAC)}

Training had a positive but not significant effect on disability in TR before surgery. After surgery, both groups reported an improvement compared with the pre-surgical condition, however, after correction for age $(\mathrm{p}<0.05)$ and sex, the effect dropped to just a trend $(F(1,63)=3.82, p=0.06, r=0.24, d=0.49$ after 4 months and $F(1,57)=3.25, p=0.08, r=0.23, d=0.47$ after one year.

\section{Sensorimotor function (Biodex Balance System)}

TR showed better mean balance ability than CO before the THEP, regarding both the overall stability index $(\mathrm{M}=2.34, \mathrm{SD}=0.55)$ compared to $\mathrm{CO}(\mathrm{M}=2.62, \mathrm{SD}=0.81)$ and the medial-lateral stability index $(\mathrm{M}=1.58, \mathrm{SD}=0.48$ and $\mathrm{M}=1.90, \mathrm{SD}=0.72$ respectively). These differences were significant $(t(67)=2.26, p<0.05$, $\mathrm{r}=0.20, \mathrm{~d}=-0.4$ and $\mathrm{t}(67)=2.15, \mathrm{p}<0.05, \mathrm{r}=0.25, \mathrm{~d}=-0.52$ respectively). TR kept better balance than CO post-surgically, both at the 4-month and the one-year follow-up point, but the differences were no longer significant.

\section{Correlations}

The 2 variables of balance before surgery, 10 days and 4 months post-surgery showed significant correlation between one another and with the one-year value (Kendall's tau 0.328-0.543, $\mathrm{p}<0.01)$. The balance ability at 10 days, 4 months and one year also showed significant correlation with physical functioning (Kendall's tau $-0.323,-0.324,-0.221, \mathrm{p}<0.01$ ).

\section{Discussion}

\section{$\nabla$}

\section{Summary of main results}

TR suffered less hip pain and showed better balance skills presurgery than CO. These benefits were lost after surgery and TR tended to assess their physical functioning, mental health and disability lower than CO. TR continued to report greater physical limitations than $\mathrm{CO}$ one year post-surgery, even though their objective balance skills were better throughout the entire postsurgical phase. The effect of group membership on mental health and vitality depended on the follow-up time point.

\section{Possible explanations}

The objective balance skills of TR were better than their subjective assessment of their physical functioning. The training may have aroused higher expectations, which TR did not consider to have been fulfilled in reality. Further, perception training may have caused sensitisation, which could have led TR to make a more critical self-assessment of their condition. Both these effects may have had an adverse influence on the mental condition of TR.

As a result, the first hypothesis is only partially supported by our findings. The trained patients acquired better balance skills and suffered less pain before surgery, but demonstrated no differences in any of the other outcomes (physical activity, disability and quality of life). The TR group retained superior objective sensorimotor skills until 4 months post-surgery, but the difference was no longer significant. They had no benefits neither in physical activities and disability nor in quality of life in this postsurgery period. One year after surgery any difference between the 2 groups was no longer found, which is in agreement with the second hypothesis.

\section{Comparison with literature}

\section{Physical functioning, quality of life and disability}

According to Gocen et al. [18], pre-surgical strength training enables TR to perform transfer activities and stairclimbing one day earlier. The self-reported abilities of the participants of our study do not confirm this. However, this could be seen as due to unfulfilled heightened expectations, leading our participants to assess their condition as worse than indicated by objective functional tests. The superior balance skills of TR seem to support this. Our results are not comparable with those of Wang [40] and Gilbey et al. [17], since their first post-surgical measurements were only taken after 3 weeks. Thereafter TR in both these studies followed an additional training programme, hence, the effect of the pre-surgical training in the different groups can no longer be compared. The systematic review by Ackerman and Bennell [2] reinforces the conclusion that the available studies - namely those of Wang and Gilbey et al. [17,40] - cannot be used to determine the effect of pre-surgical training on patients undergoing THEP. 
The most recent study [34], where a 6-week pre-surgical strength, endurance and flexibility training programme was followed, reports significant pre-surgical improvement of the WOMAC global index and SF-36 physical functioning in TR, but no significant differences in the SF-36 pain, or in balance and strength. Eight and 26 weeks after the procedure, differences were no longer observed. In contrast, our study showed significant improvements in pain and balance skills after the training programme. This indicates that the sensorimotor programme seems more suitable to influence pain and balance than a strength and endurance programme.

TR of our study assessed their functional status post-surgery as worse than that of $\mathrm{CO}$, even though the opposite might have been expected in view of their superior balance skills. Participants in TR could have had high expectations because their presurgical condition was better than that of CO. Mancuso et al. [26] established a link between lower post-surgical satisfaction and better pre-surgical physical conditions. Patients should be more carefully briefed before surgery on realistic expectations and the likely course of post-surgical events [25,27]. Several studies indicate that satisfaction with a hip replacement is a complex phenomenon and is related to expectations, results and knowledge about the procedure. Pre-surgical information and instruction programmes support physical and psychological processes. They reduce fear, lead to more balanced expectations and increase the ability to develop coping strategies, which in turn promotes physical recovery $[8,10,15,16,36]$.

Does a sensorimotor exercise programme affect body related self-evaluation? Beginners tend to check their movements visually, while those with greater exercise experience tend to make more use of their proprioceptive (kinaesthetic) system. Any kind of exercise training can improve proprioceptive function, which leads to increased differentiated muscle activity and more precise spatial awareness of the position of the trunk and the extremities [41]. Such skills may also make participants more aware of limitations on their movements and lead to more sensitive critical self-appraisal.

\section{Sensorimotor function}

The measurements performed 10 days after surgery indicate that those who underwent training lost two-thirds of the balance skills they had gained pre-surgery, while those who did not undergo training remained at the same level. Several authors $[23,31,42]$ have found that proprioception skills remain intact following hip replacement. However, sensorimotor function for more complex activities have been shown to be more limited than in healthy individuals [31]. This apparent discrepancy between findings can be explained by the differences between the concepts of proprioception and the sensorimotor system. Proprioception refers only to afference, i.e., the acquisition of sensory input by peripheral receptors and the transmission of neurological signals to the central nervous system. By contrast, the sensorimotor system includes the entire complex of both afference (sensory pathways) and efference (motor pathways) that are involved with the neuromuscular response [24]. Nallegowda et al. [31] conclude that proprioception depends on capsular receptors on the one hand and afferent signals from muscles, tendons and ligaments on the other hand so that capsulectomy needs not adversely affect proprioceptive feedback. Nevertheless tests for complex sensorimotor tasks, performed in a dynamic environment 10 months after hip replacement, showed that those with prosthetic joints had a neuromotor defi- cit and required additional input from their visual and vestibular systems. They compensate for the reorganisation of the central sensorimotor process following joint replacement. Thus maintaining one's balance on an unstable surface on the tenth day after surgery could still represent a task too complex to use the patient's recently gained capacity. By 4 months and one year after surgery, both groups have improved their sensorimotor skills to the extent that they can keep their balance better than before surgery. The TR then still retains two-thirds of the benefit it had over the control group pre-surgically. The results of Illyés and colleagues [22] support our findings by showing that sensorimotor skills were worse 2 weeks after the hip replacement, while 12 weeks after surgery the participants showed better skills than before.

The training period in our study may seem rather short, but was limited by the hospital's organisational framework. Studies have confirmed the beneficial effects of sensorimotor training programmes lasting 6-12 weeks [19]. Although the results suggested that the majority of patients in TR indeed showed a sufficient response after the minimal intervention program before surgery, the quantity of the training intervention might still not have been enough to generalize and consolidate this initial rapid response over a longer period of time in order to outweigh the influences of surgery and to surpass the standard post-surgery rehabilitation effect.

The promotion of good pre-surgical balance skills is a worthwhile activity. The correlations we found indicate a direct relation to post-surgical balance skills and physical functioning, as supported by the statements made by Granacher and Gollhofer [19] mentioned in the introduction section. To the best of our knowledge, the present study is the first one in THEP to make use of balance data obtained with the aid of the Biodex Balance System.

\section{Study limitations}

For the convenience of the participants, the follow-up checks were performed at the same time as the regular medical checks. No measurements were taken at the time of registration for participation in this trial, or before the training exercises, to save $\mathrm{CO}$ an additional visit to the clinic. If these measurements had been performed, the participants with the shortest training time would have had to undergo 3 sets of measurements within 25 days, which could lead to results of doubtful validity for the questionnaires. As a result of this procedure, any differences between the groups at the time of registration could not be taken into account. Furthermore, it could have been too early to perform the measurement 10 days after the hip replacement surgery for measuring the training effect, because the acute sequelae of the procedure are still prominent. At least the 10 th day proved too early for several patients to take the balance test. They found it difficult to complete this test due to pain and circulatory problems. Others were already discharged from the hospital on day 8 or 9 , so in these cases the test had to be brought forward. Moreover, self-reported data on pain during the stationary period could be strongly influenced by any pain-killers taken, and must therefore be interpreted with caution. In addition, a considerable amount of the items concerning physical functioning and pain had to be removed from the SF-36 and WOMAC questionnaires for the 10-day check, which may have limited the reliability of the data derived from this questionnaire. For these reasons, it may be assumed that performing the 
first check 3-4 weeks after surgery instead of 10 days after might have led to more meaningful results.

The instructors assigned the participants to the trial groups after randomisation, and were also responsible for the investigation. In order to remove any possible bias as much as possible, we chose measuring instruments that were independent of the investigators, namely self-administered questionnaires and an objective balance test.

The design of this study was based on natural observation similar to that encountered in daily clinical practice. This may have led to a smaller effect size, but has the advantage of being more realistic than a study with a strictly monitored therapy programme.

\section{Generalisability}

The controlled randomisation, the comparability of the participant characteristics with those given in other studies $[10,17,40]$, the use of internationally accepted questionnaires used for the outcome measures, as well as the participation of patients from several surgeons, all increased the generalisability of the results presented here concerning patients undergoing their first hip replacement surgery. The one-year observation period is relatively long. The facts that the sample studied was adequate from a statistical point of view but still relatively small and that only persons undergoing unilateral hip replacement and coming from a rural environment could be considered, may on the other hand have limited the generalisability of the study.

\section{Conclusion}

The only systematic review of studies on pre-surgical training before THEP confirms the unclear effect after hip replacement. The aim of the present study was to offer a standard pre-surgical sensorimotor training programme involving minimum effort for the participants to promote good physical functioning and sensorimotor abilities. This training programme was found to be successful in improving balance skills and reducing pain before the intervention, but did not provide any benefit in terms of self-evaluated daily functioning or quality of life following surgery. In contrast, however, objective measurements showed a slightly better sensorimotor outcome in TR. Psychosomatic processes seem to play a role in explaining these contradictive findings. Further research is needed to reveal whether an individually tailored progressive home training programme would have a better effect. The psychological aspects of a hip replacement surgery should also be given due consideration to counter unrealistic expectations, promote coping strategies and increase patient satisfaction.

\section{Acknowledgements}

\section{$\nabla$}

We would like to express our hearty thanks to all the participants in this study, to E. Hanafi, S. Häfliger, M. Lüem, the physiotherapy team, Professor P. E. Ochsner and Associate Professor T. Ilchmann, and finally to the research committee of the Swiss Physiotherapy Association for the grant that made it possible for us to use the Biodex Balance System. The CONSORT statement $[2,29]$ was followed in the preparation of this article. The authors received no emoluments apart from their clinical salaries. A German language adapted version of this paper was published in Phys Med Rehab Kuror 2009, 19: 1-9 [5].

\section{References}

1 Bundesamt für Statistik (BFS). Krankenhausbehandlung - Detaillierte Daten. 2008. Neuchatel, Switzerland. http://www.bfs.admin.ch/bfs/ portal/de/index/themen/14/04/01/data/01.html

2 Ackerman IN, Bennell KL. Does pre-operative physiotherapy improve outcomes from lower limb joint replacement surgery? A systematic review. Aust J Physiother 2004; 50: 25-30

3 Angst F, Aeschlimann A, Stucki G. Smallest detectable and minimal clinically important differences of rehabilitation intervention with their implications for required sample sizes using WOMAC and SF-36 quality of life measurement instruments in patients with osteoarthritis of the lower extremities. Arthritis Rheum 2001; 45: 384-391

4 Arnold BL, Schmitz RJ. Examination of balance measures produced by the biodex stability system. J Athl Train 1998; 33: 323-327

5 Bachmeier CJ, March LM, Cross MJ, Lapsley HM, Tribe KL, Courtenay BG, Brooks PM. A comparison of outcomes in osteoarthritis patients undergoing total hip and knee replacement surgery. Osteoarthritis Cartilage 2001; 9: 137-146

6 Boardman DL, Dorey F, Thomas BJ, Lieberman JR. The accuracy of assessing total hip arthroplasty outcomes: a prospective correlation study of walking ability and 2 validated measurement devices. J Arthroplasty 2000; 15: 200-204

7 Bullinger M, Kirchberger I. SF-36 Fragebogen zum Gesundheitszustand Handanweisung. Götingen: Hogrefe Verlag für Psychologie; 1998

8 Butler GS, Hurley CA, Buchanan KL, Smith-VanHorne J. Prehospital education: effectiveness with total hip replacement surgery patients. Patient Educ Couns 1996; 29: 189-197

9 Cohen J. Statistical Power Analysis for the Behavioral Sciences. $2^{\text {nd }}$ edition. Hillsdale, NJ: Lawrence Erlbaum Associates; 1988

10 Crowe J, Henderson J. Pre-arthroplasty rehabilitation is effective in reducing hospital stay. Can J Occup Ther 2003; 70: 88-96

11 Fagerson T. The Hip Handbook. Boston: Butterworth-Heinemann; 1998

12 Finch E, Brooks D, Stratford P, Mayo N. Physical Rehabilitation Outcome Measures - A Guide to Enhanced Clinical Decision Making. ( $2^{\text {nd }}$ edition). Hamilton: BC Decker Inc.; 2002

13 Finn J, Alvarez $M$, Jett $R$, Axtell $R$, Kemler D. Stability performance assessment among subjects of disparate balancing abilities. Med Sci Sports Exerc 1999; 31: S252

14 Fisher R, Yates F. Statistical Tables for Biological, Agricultural and Medical Research. Darien: Hafner Publishing Company; 1970

15 Gammon J, Mulholland CW. Effect of preparatory information prior to elective total hip replacement on post-operative physical coping outcomes. Int J Nurs Stud 1996; 33: 589-604

16 Gammon J, Mulholland CW. Effect of preparatory information prior to elective total hip replacement on psychological coping outcomes. J Adv Nurs 1996; 24: 303-308

17 Gilbey HJ, Ackland TR, Wang AW, Morton AR, Trouchet T, Tapper J. Exercise improves early functional recovery after total hip arthroplasty. Clin Orthop 2003; 193-200

18 Gocen Z, Sen A, Unver B, Karatosun V, Gunal I. The effect of preoperative physiotherapy and education on the outcome of total hip replacement: a prospective randomized controlled trial. Clin Rehabil 2004; 18: $353-358$

19 Granacher U, Gollhofer A. Neuromuskuläre Leistungsfähigkeit im Alter Ein Überblick. Zeitschrift für Physiotherapeuten 2005; 57: 1316-1328

20 Harriss DJ, Atkinson G. International Journal of Sports Medicine - Ethical Standards in Sport and Exercise Science Research. Int J Sports Med 2009; 30: 701-702

21 Hinman M. Factors affecting reliability of the Biodex Balance System: a summary of four studies. J Sport Rehabil 2000; 9: 240-252

22 Illyés À, Holnapy G, Szendröï M, Kiss R. Importance of proprioception after total hip replacement. In: Proceedings of the $24^{\text {th }}$ IASTED International Conference on Biomedical Engineering. Austria: International Association of Science and Technology for Development; 2006; 379-383

23 Ishii Y, Tojo T, Terajima K, Terashima S, Bechtold JE. Intracapsular components do not change hip proprioception. J Bone Joint Surg Br 1999; 81: 345-348

24 Lephart S, Fu F. Proprioception and Neuromuscular Control in Joint Stability. Leeds: Human Kinetics; 2000

25 Lieberman JR, Dorey F, Shekelle P, Schumacher L, Thomas BJ, Kilgus DJ, Finerman GA. Differences between patients' and physicians' evaluations of outcome after total hip arthroplasty. J Bone Joint Surg Am 1996; 78: 835-838

26 Mancuso CA, Salvati EA, Johanson NA, Peterson MG, Charlson ME. Patients' expectations and satisfaction with total hip arthroplasty. J Arthroplasty 1997; 12: 387-396 
27 Mancuso CA, Sculco TP, Salvati EA. Patients with poor preoperative functional status have high expectations of total hip arthroplasty. J Arthroplasty 2003; 18: 872-878

28 McGrath RE, Meyer GJ. When effect sizes disagree: the case of $\mathrm{r}$ and d. Psychol Methods 2006; 11: 386-401

29 Moseley GL. Do training diaries affect and reflect adherence to home programs? Arthritis Rheum 2006; 55: 662-664

30 Nakagawa S, Cuthill IC. Effect size, confidence interval and statistical significance: a practical guide for biologists. Biol Rev Camb Philos Soc 2007; 82: 591-605

31 Nallegowda M, Singh U, Bhan S, Wadhwa S, Handa G, Dwivedi SN. Balance and gait in total hip replacement: a pilot study. Am J Phys Med Rehabil 2003; 82: 669-677

32 Nilsdotter AK, Roos EM, Westerlund JP, Roos HP, Lohmander LS. Comparative responsiveness of measures of pain and function after total hip replacement. Arthritis Rheum 2001; 45: 258-262

33 Pincivero D, Lephart S, Henry T. Learning effects and reliability of the Biodex Stability System. J Athl Train 1995; 30: S48

34 Rooks DS, Huang J, Bierbaum BE, Bolus SA, Rubano J, Connolly CE, Alpert S, Iversen MD, Katz JN. Effect of preoperative exercise on measures of functional status in men and women undergoing total hip and knee arthroplasty. Arthritis Rheum 2006; 55: 700-708

35 Schmitz R, Arnold B. Intertester and intratester reliability of a dynamic balance protocol using the Biodex Stability System. J Sport Rehabil 1998; 7: 95-101
36 Siggeirsdottir K, Olafsson O, Jonsson H, Iwarsson S, Gudnason V, Jonsson $B Y$. Short hospital stay augmented with education and home-based rehabilitation improves function and quality of life after hip replacement: randomized study of 50 patients with 6 months of follow-up. Acta Orthop 2005; 76: 555-562

37 Soderman $P$, Malchau $H$, Herberts $P$. Outcome of total hip replacement: a comparison of different measurement methods. Clin Orthop 2001; 163-172

38 Stucki G, Meier D, Stucki S, Michel BA, Tyndall AG, Dick W, Theiler R. Evaluation einer deutschen Version des WOMAC (Western Ontario und McMaster Universities) Arthroseindex. Z Rheumatol 1996; 55: 40-49

39 van Baar ME, Dekker J, Oostendorp RA, Bijl D, Voorn TB, Lemmens JA, Bijlsma JW. The effectiveness of exercise therapy in patients with osteoarthritis of the hip or knee: a randomized clinical trial. J Rheumatol 1998; 25: 2432-2439

40 Wang AW, Gilbey HJ, Ackland TR. Perioperative exercise programs improve early return of ambulatory function after total hip arthroplasty: a randomized, controlled trial. Am J Phys Med Rehabil 2002; 81: 801-806

41 Weineck J. Sportbiologie. Balingen: Spitta Verlag GmbH; 2000

42 Weitbrecht WU, Rice C, Schafer W. Phantomsensationen und peripher induzierter Neglect nach Hufttotalendoprothese. Fortschr Neurol Psychiatr 2004; 72: 93-97 